\title{
A New Kind of Bi-Directional Three-Port DC-DC Converter for Vehicle
}

\author{
Yi Xie, Wenguang Luo \\ School of Electrical and Information Engineering, \\ Guangxi University of Science and Technology, Liuzhou 545006, China \\ 495063861@qq.com,.wg168@126.com
}

\begin{abstract}
This paper presents the design of a new bidirectional DC-DC converter topology, which solves the problem that electric vehicle could not run consistently both in time and distance. This DC-DC converter topology has three ports, each of which can transmit electric power to another port independently, By adopting the suggested method, the running time of the electric vehicle can be extended. Moreover, the topology uses phase shift control, indicating that the IGBT can be achieved by soft-switching technology. It enables us to reduces the current stress and switching loss considerably. Finally, this paper uses Simulink module of Matlab to simulate the process, and shows the experimental result. And the result shows us the DC-DC converter has great efficiency.
\end{abstract}

Keywords-component; bi-directional DC-DC converter; three ports; soft-switching; simulation

\section{INTRODUCTION (HEADING 1)}

In the 21st century, the technology level of human society is developing rapidly. The energy consumption is also more and more intense, which has brought serious environmental pollution problems. This problem has led people to deal with the excessive energy consumption, and has to use energy more cautiously. The invention of new energy vehicles can decrease energy consumption and reduce pollution. It has become a crucial industry in the world.

DC-DC converter is a core component in the new energy automotive power systems. The main function is to pass the electrical energy from the battery or super capacitor to the motor load, and therefore drive the vehicle, It can also feedback the mechanical energy to the automobile power when the motors brake so the car can run longer distances. It is the "transfer station" of electric vehicles power and energy.

In this paper, we improved a vehicle bi-directional fullbridge DC-DC converter topology. At the same time, we added one port to the two ports system and discussed the feasibility of vehicle three ports bi-directional full-bridge DC-DC converter, We also used soft-switching, to reduce the current stress of IGBT, which could extend the service life of electric vehicle power system.

Unidirectional DC-DC converter can pass energy only from one direction to another direction. Thus, it is not applicable of the principle of energy feedback. Therefore, we decide to use the bi-directional DC-DC converter system ${ }^{[1]}$.

We can send different instructions to the new energy vehicles by using bi-directional DC-DC converter. It can absorb the electricity power of battery, and make the power output. It can also convert mechanical energy to electric power and feed back to the battery.
At the same time, vehicle DC-DC converter's working environment is a serious problem. Since switching frequency is very high, IGBT switch would bear high current stress and switching loss. It will affect the service life of the DC-DC converter system, Using soft switching control technology can solve the current stress problem very effective ${ }^{[2]}$.

Bi-directional DC-DC converter is categorized as isolated form DC-DC converter and non-isolated form converter, Isolated form DC-DC converter is more suitable for high and medium power convert situation, because electric circuit design of the separation of input terminal and output terminal, is more flexible, When the input and output fail separately, they do not influence each other, which can protect the battery and automobile motor. This is necessary for the stable and secure running of electric vehicles ${ }^{[3]}$.

The features of batteries are soft. It cannot fully satisfy the acceleration or climbing requirements at a certain particular time, Super-capacitors have the ability to provide greater power output to the automobile, and a lot of modern automobiles have a double bus input, therefore, it is appropriate to design the topology as a three-port bidirectional full-bridge DC-DC converter for the new energy efficient vehicles ${ }^{[4]}$.

\section{THREE-PORT BI-DIRECTIONAL FULL-BRIDGE DC-DC CONVERTER TOPOLOGY}

Three-port bi-directional full-bridge converter has two inputs. It can be a battery and a super capacitor, it can also be double-bus. This topology has flexible features. The electricity power can not only be passed between battery and motor load, or super capacitor and motor load, but also can be passed between battery and super capacitor just in case the emergence of a low-battery emergency. This circuit has a multi-function effect.Fig.1 shows the DC-DC converter topology ${ }^{[5]}$.

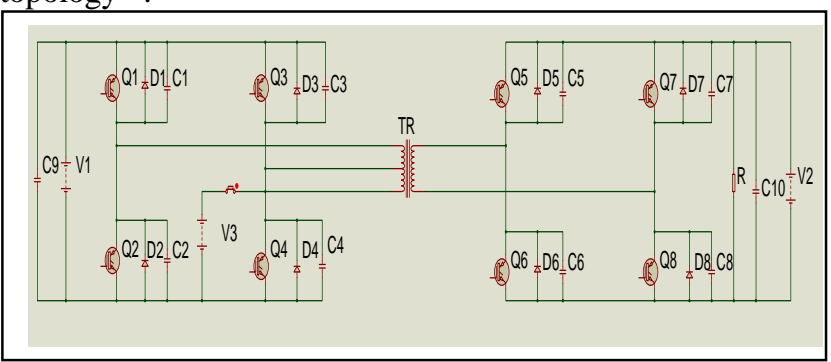

Figure 1. DC-DC converter topology

Because the transmission of power and energy is mainly achieved by the leakage inductance of transformer, we could 
equalize the transformer to inductor models, and we can get the following schematic as Fig.2.

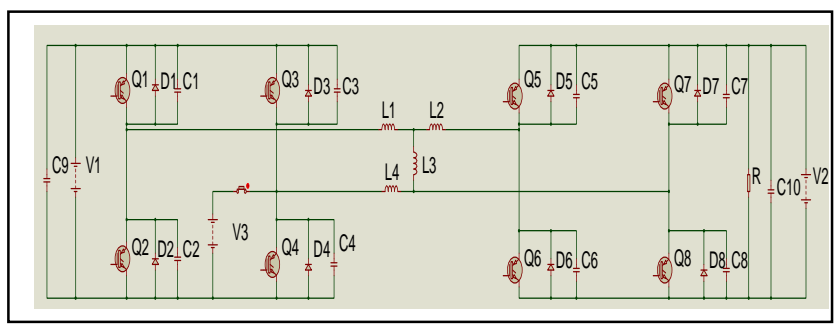

Figure 2. Equivalent of DC-DC converter topology

Because a lot of modern cars have battery and super capacitor at the same time, we use this structure as an example.

The operation mode analyzed in energy transfer could be divided into three parts. The first part is the energy transfer between the battery and the load R. The second part is the energy transmission between the super capacitor and the load $\mathrm{R}$, The third part is energy transfer between the battery and the super capacitor.

\section{A. Principle Analysis of energy transfer from the battery to the load}

Make the following assumptions:

(1) All switch, and diodes are ideal elements;

(2)All inductors, capacitors, and transformers are ideal elements;

When the battery transmits power, switch $S_{1}$ is closed, and switch $S_{2}$ is turned off. At this moment, $V_{2}$ does not work. Transformer connected to it does not work too.

A switching period of the DC-DC converter can be divided into six steps. We can analyze the transmission process of the forward impedance power.

$t_{0}-t_{1:}$ At time $t_{0}$,IGBT $Q_{1}, Q_{4}$ close, and diode $D_{5} D_{6}$ is working. At that moment, The value of the capacitor voltage parallel connect $Q_{1}, Q_{4}$ is zero, the capacitors voltage parallel connect $Q_{2}, Q_{3}$ is charged. Its value is equal to $V_{1}$. The current on primary side passes from the cathode of $V_{1}$ to $Q_{1}$, and then to leakage inductance $L_{1}$, and then to $Q_{4}$ and at last back to the anode of $V_{1}$. The current on the secondary side is passed from the cathode of excitation inductance $L_{3}$ to leakage inductance $L_{2}$, diode $D_{5}$, power supply $V_{2}$ load $R$ and filter capacitor $C_{10}$,to diode $D_{8}$, and at last back to the anode of $L_{3}$

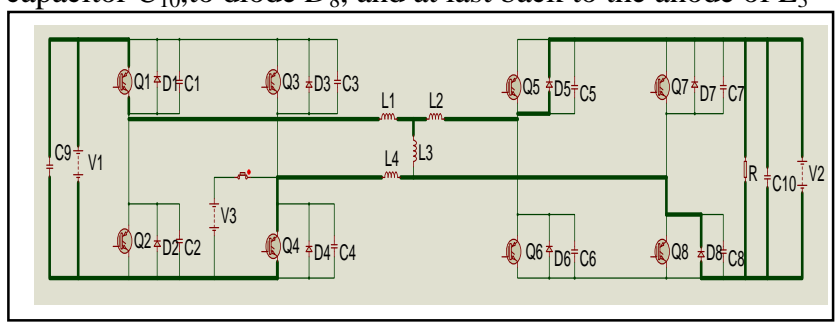

Figure 3. Equivalent circuit diagram at $t_{0}-t_{1}$

$t_{1}$ - $t_{2:}$ At time $t_{1}, Q_{1}$ and $Q_{4}$ is turned off, the value of the the capacitors voltage parallel connect $Q_{1}, Q_{4}$ is zero at the beginning, and it cannot change suddenly.Thus, $Q_{1}, Q_{4}$ zero voltages turn off(ZVS).Then $C_{1}, C_{4}$ begin to be charged, $C_{2}$, $C_{4}$ are discharged, and the current of excitation inductance cannot change immediately, so the current direction is constant. Some current still passes the switch tube $Q_{2}, Q_{3}$. At this moment, all four IGBTs of the primary side are turned off, and the original side voltage decreases continuously. At time $t_{2}, Q_{1}$ and $Q_{4}$ are closed, because of the effect of current reflowing of $D_{2}, \quad D_{3}, \quad Q_{2}, \quad Q_{3}$ zero voltage working.

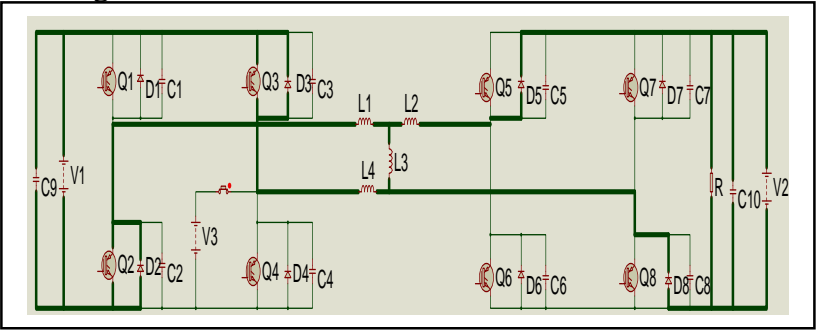

Figure 4. Equivalent circuit diagram at $t_{1}-t_{2}$

$t_{2}-t_{3}$ : At the moment of $t_{3}$, excitation inductance current decrease to zero. Its current direction reverses, IGBT $Q_{5} Q_{8}$ zero current working (ZCS), $C_{5}, C_{8}$ are discharged, $C_{6}, C_{7}$ are charged. At the end of $t_{3}, Q_{5}, Q_{8}$ are turned off, because the value of voltage of $C_{5}, C_{8}$ has been discharged to zero. Therefore, $Q_{5}, \quad Q_{8}$ zero voltage turns off.

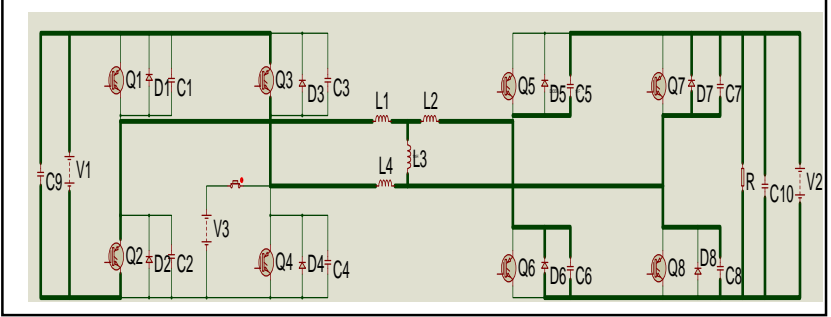

Figure 5. Equivalent circuit diagram at $t_{2}-t_{3}$

$t_{3}-t_{4}$ : At the beginning of $t_{4}$,IGBT $Q_{2}, Q_{3}$ are closed. Diode $D_{6}, D_{7}$ are working, in the end of $t_{4}, Q_{2}, Q_{3}$ are turned off. In this process, the voltage of $C_{2}, C_{3}$ cannot change immediately, $Q_{2}, Q_{3}$ zero voltage turn off. Then $C_{2}, C_{3}$ begin to be charged, $C_{1}, C_{4}$ are discharged. The primary side voltage rises, the primary side inductor current rises too, Diode $D_{1}, D_{4}$ current reflows. Excitation inductance current cross zero.

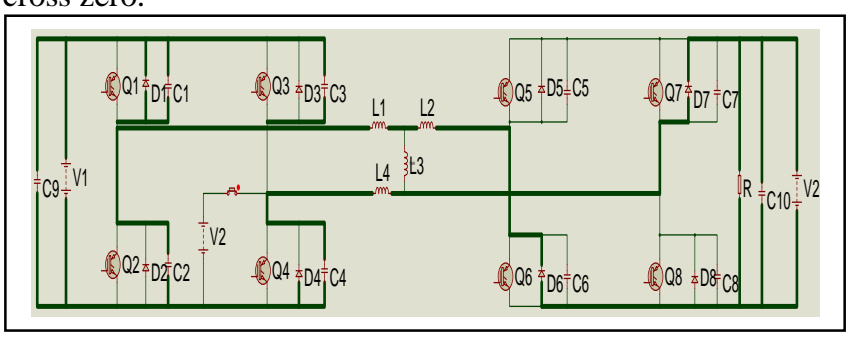

Figure 6. Equivalent circuit diagram at $t_{3}-t_{4}$

$t_{4}-t_{5}$ : Because the reflowing effect of $D_{1}$ and $D_{4}$ current, at $t_{5}$,IGBT $Q_{1}$ and $Q_{4}$ zero current work. In the end of $t_{5}, Q_{6}$ and $Q_{7}$ are closed, because the inductance current is crossing 
zero at that moment. So $Q_{6}, Q_{7}$ zero voltage working $C_{6}$ and $C_{7}$ are discharged, $C_{7}$ and $C_{8}$ are charged.

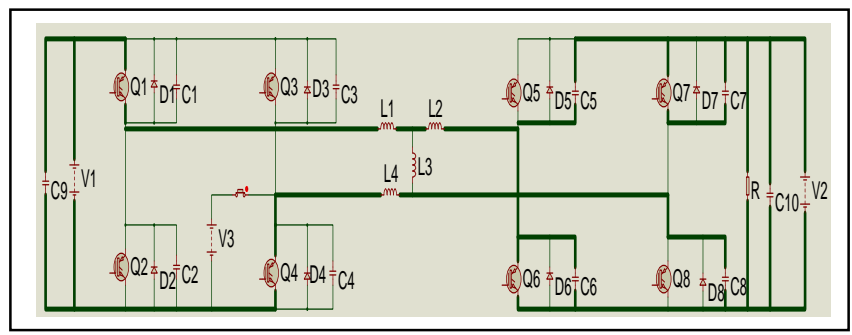

Figure 7. Equivalent circuit diagram at $t_{4}-t_{5}$

$t_{5}-t_{6}: Q_{6}$ and $Q_{7}$ are turned off, because $C_{6}, C_{7}$ has been discharged to zero in the early time. So $Q_{6}$ and $Q_{7}$ zero voltage turns off. Diode $\mathrm{D}_{5}$ and $\mathrm{D}_{8}$ current is reflowing, At time $t_{6}, Q_{1} Q_{4}$ are closed. Back to the moment of $t_{1}$ state, the circuit goes into the next period.

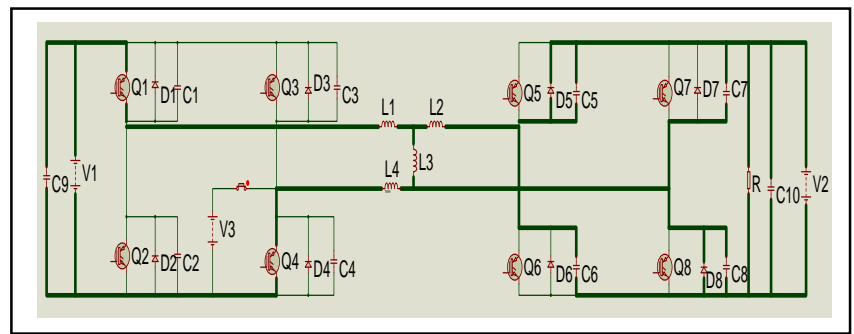

Figure 8. Equivalent circuit diagram at $t_{5}-t_{6}$

The reverse transmission process is similar, so as the transmission process of super capacitor $V_{3}$ to $V_{2}$. Further discussion is not necessary in this paper.

\section{B. Mechanism of battery and super capacitor transmit energy}

After the automotive has worked for a long time, the battery power becomes very low. Now we can use super capacitor to transmit power to the battery. It is difficult to control, and the excessive elements will lead to some unnecessary energy loss. So we choose non-isolated DC-DC converter circuit for the task, and each power supply series connects switch $\mathrm{S}_{1}$ or $\mathrm{S}_{2}$. If one part of the power supply goes wrong, the switch will be turned off immediately to protect the other power supply. The equivalent topology is shown below.

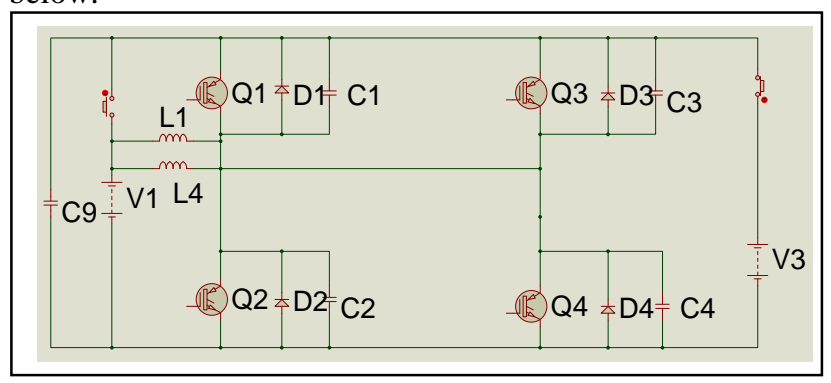

Figure 9. $V_{1}-V_{3}$ equivalent circuit diagram topology

In the forward power transmission mode, the circuit is BOOST, $Q_{2}, Q_{4}, D_{1}, D_{3}$ are working to convert current.
$Q_{1}, Q_{3}, D_{2}, D_{4}$ are turned off. $Q_{2}$ and $Q_{4}$ drive pulses are different from 180 degrees, When the power transmit reversely, the circuit is BUCK, $Q_{1}, Q_{3}, D_{2}$ and $D_{4}$ convert current, $Q_{2}, Q_{4}, D_{1}, D_{3}$ are turned off, Just opposite to forward power transmit, this bi-directional DC-DC converter is staggered by bi-directional DC-DC converters. The advantages are simple structure, high transmission efficiency, good heat dispersion and so on.

\section{NUMERIACL SIMULATION}

As a powerful tool of the computer simulation of control theory, Simulink is an expansion of Matlab, Its model graphic input system can help users establish the system model more conveniently, So using SimPowerSystems module in Simulink is an ideal way to simulate the circuit in this paper. Fig 10 is the simulation model of vehicle threeport bi-directional full-bridge DC-DC converter.

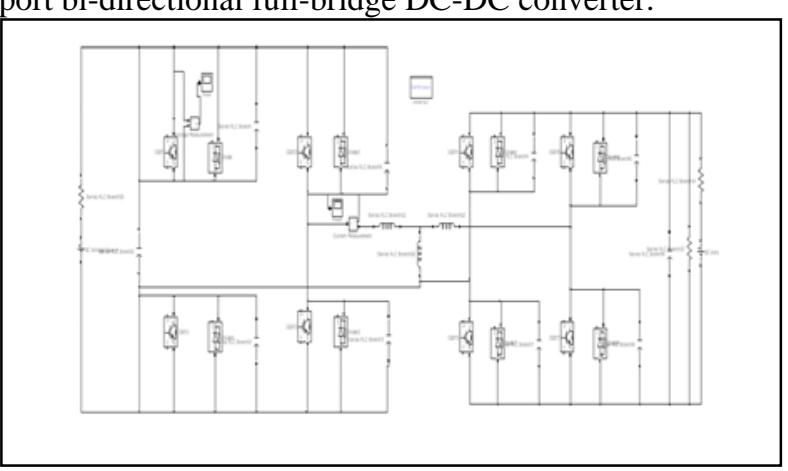

Figure 10. Schematic of simulation

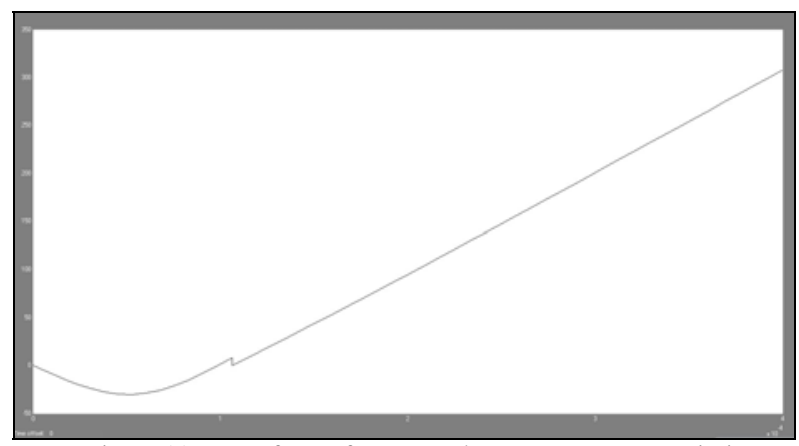

Figure 11. Waveform of output voltage $V_{1}$ t to $V_{2}$ transmission

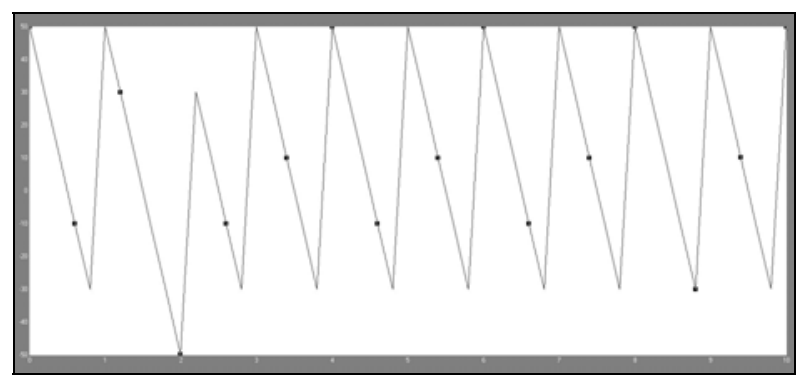

Figure 12. Waveform of output current $V_{1}$ to $V_{2}$ transmission 


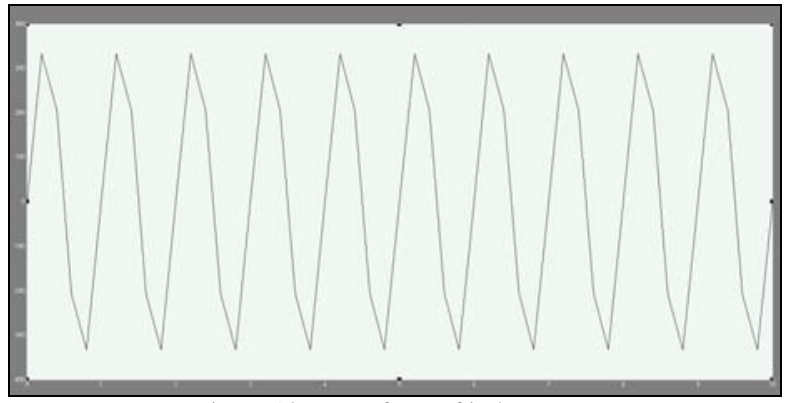

Figure 13. Waveform of inductor current

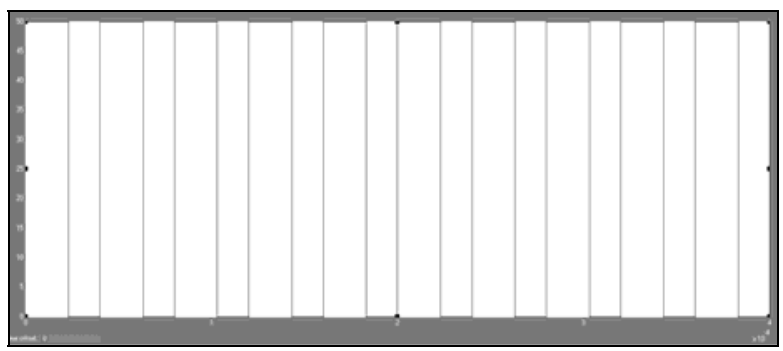

Figure 14. Waveform of IGBT pulse signal

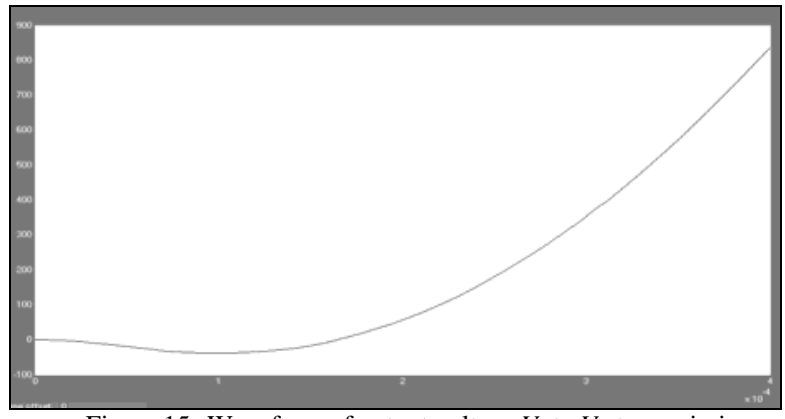

Figure 15. Waveform of output voltage $V_{1}$ to $V_{3}$ transmission

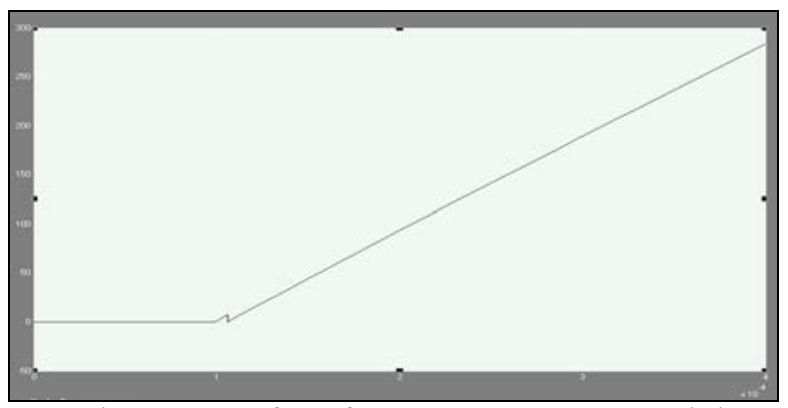

Figure 16. Waveform of output current $V_{1}$ to $V_{3}$ transmission

We can get the following information from the figures above. The circuit topology is stable. Every element work safely, The inductor current has some disturbance in a short time, but returns to normal rapidly, Moreover the waveform of output voltage and output current has some small ripple. The system appears a little amplitude of quake in regulating process. These quakes are actually created by time delay of control system. After regulating, the system becomes normal. The voltage of IGBT could be zero in the right. It is a soft switching control.

\section{CONCLUSIONS}

This paper provides an improved topology of a vehicle bidirectional full-bridge DC-DC converter. The direct current can transmit among the three ports efficiently. We use the phase-shift control. When the IGBT turns off or closes, the voltage or current on it is zero. It reduces the current stress of IGBT, and extends service life, At last, it makes the energy transfer between the battery and super capacitor, and increases the efficiency of battery usage and super capacitor energy, and therefore optimizes the electric vehicle power systems.

\section{ACKNOWLEDGMENT}

This work is supported by Guangxi Science Foundation Grant (No. 0832067) and supported by the Opening Project of Guangxi Key Laboratory of Automobile Components and Vehicle Technology (No. 2012KFZD03).

\section{REFERENCES}

[1] Manu Jain,Praveen K.Jain,Matteo Daniele.Analysis of a bidirectional DC-DC converter topology for low power application[A]. CCECE.1997:548-551.

[2] Chan H. L.,Cheng K. W. E.,Sutanto D.Bidirectional phase-shifted DC/DC converter. IEEE Electronics Letters 1st,1999, 35(7):523-524.

[3] Ziogas P D,Prasad A R,Manias S.Analysis and design of a three phase off-line DC-DC converter with high frequency isolation.IEEE Trans. on Industry Applications,1992,28(4):824-832

[4] JINW, FANG Z P,JOEL A,et a.l Low cost fuel cell converter system for residential power generation.IEEE Transactions on Power Electronics, 2004, 5(19):1 315-1 322.

[5] CalventeJ,Giunjoan F,Martinez L,et al.Subharmonics bifurcationsand chaos in a sliding-mode controlled.boost switching regulator. Proc.IEEEInt.Symp,Circuitsand Systems,Atlanta,GA,1996.

[6] Pavljasevic S, Martinez D. Using a discrete-time model for largesignalanalysis of a current-programmed boost converter. Proc. IEEEpower Electronics Specialists Conf, 1991

[7] Chan W C Y, Tse C K. Bifurcations in current-progammedDC/DC Buck switching regulators-conjecturing a universal bifurcationpath [J] . Int.J.Circuit Theory and Applications, 1998, 26(1) : 127-145.

[8] Kassaian J G,Schlecht M F,Verghese GC.Principles of PowerElectronics Reading .MA:Addison-Wesley,1991

[9] Deane J H B.Chaos in current-mode controlled boost dcdcconverter.IEEE Trans. on Circuits Syst.I,1992,39(8):680-683 